HISTÓRIA DA FILOSOFIA

\title{
Narratividade histórica e natureza humana em Hume
}

Historical narrativity and human nature in Hume

* Fabiano Lemos

\begin{abstract}
Resumo: O artigo pretende discutir o estatuto da narratividade na obra de Hume, não apenas como metodologia, mas como o único meio através do qual a natureza humana ela mesma pode ser abordada no interior de seu projeto de uma ciência do homem. Em uma perspectiva exclusivamente empírica, a história se revela como o nível de composição de narrações - tanto no estudo dos costumes quanto ao lidar com a formação das relações de ideias. A leitura de muitos comentadores de Hume, que dissociam o Tratado da História da Inglaterra como dois desenvolvimentos separados de uma escrita heterogênea, pode ser desconstruída, assim, através de uma consideração atenta do que está em jogo nas demandas de objetividade no contexto da historiografia pós-rankeana.
\end{abstract}

Palavras-chave: Hume. Narratividade. Natureza humana.

\begin{abstract}
The paper discusses the statute of narrativity not only as methodology in Hume's work, but as the only way human nature itself can be approached within his project of a science of man. In an exclusively empirical perspective, history is revealed as the level of composing narrations - both in a study of costumes and in dealing with the formation of relations of ideas. The reading of many modern scholars on Hume, that sets apart the Treatise from History of England, as two separate branches of a heterogeneous writing, could be played down by attentive consideration of what is at stake in the demands of objectivity in the context of post-Rankean historiography.
\end{abstract}

Keywords: Hume. Narrativity. Human nature.

* Doutor em Filosofia. Professor de Filosofia no Departamento de Filosofia da UERJ. $<$ fabianolemos@gmail.com>. 
"It stands. What? Yes. Say it stands. Had to up in the end and stand. Say bones. No bones but say bones. Say ground. No ground but say ground. So as to say pain. No mind and pain? Say yes that the bones may pain till no choice but stand. Somehow up and stand. Or better worse remains. Say remains of mind where none to permit of pain. Pain of bones till no choice but up and stand. Somehow up. Somehow stand. Remains of mind where none for the sake of pain. Here of bones. Other examples if needs must. Of pain. Relief from. Change of."

SAMUel BeCKetT, Worstward Ho. Para Ulysses, primeiro. E para Thomas Bernhard, depois.

\section{Introdução}

H m 1824, no prefácio da primeira edição de sua Geschichte der IJ romanischen und germanischen Völker, Leopold von Ranke formulou uma das passagens mais repetidas da historiografia dos cem anos que lhe seguiram:

A forma deriva da perspectiva e do conteúdo [Absicht und Stoff]. Não se pode exigir da história [Historie] um desenvolvimento livre como o que a teoria ao menos procura na obra poética; e não sei se, por direito, se pode acreditar ter encontrado algo assim nas obras dos mestres gregos e latinos. Apresentação rigorosa dos fatos, tão incompletos e feios [bedingt und unschön] quanto forem, é, sem dúvida, a lei máxima" (RANKE, 1885, p. VII).

Transformada em regra do protocolo científico, tal passagem pretendia, enfim, resgatar a história das impurezas e dos exageros do estilo do século 18. Confrontada com a maneira como Hume ou Voltaire procuraram compor as suas narrativas, por exemplo, a nova exigência de Ranke se apresentava como uma ruptura metodológica que constituiu, ao menos do ponto de vista de sua representação no imaginário científico europeu desde o final do século 19, o marco inaugural da história propriamente moderna. Já não havia mais espaço para o "agradável entretenimento para a mente" que Hume propunha como um dos mais importantes argumentos a favor do estudo histórico (Essays, p. 565¹). É por essa razão que, mais de quarenta anos mais tarde, quando Ranke publicou os volumes de suas lições sobre a história da Inglaterra, por um lado, reconheceu em Hume um primeiro e mais elaborado esforço de escrever

1 As abreviaturas utilizadas neste artigo referentes às obras de Hume encontram-se listadas nas referências. 
uma história ampla da Inglaterra, mas, por outro, não pôde omitir a crítica a seu método - como, por exemplo, quando aponta que os seus textos, muitas vezes, tomam como efetivamente dito - ou seja, como um fato aquilo cujo registro se dava apenas indiretamente. Tal defeito, que, aliás, é quase desculpado, na medida em que Ranke o remete ao modo como "a historiografia de sua época lhe permitiu fazer" (RANKE, 1870, p. 332), envia, em um só gesto, toda a narrativa épica dos séculos 17 e 18, de Clarendon a Voltaire, à pré-história da Historie. A graciosidade poética do estilo, que fazia das vidas de Luís XIV, Jaime VI ou Carlos I, das batalhas na Irlanda seiscentista, dos pactos régios e das intrigas e traições na Escócia dos Stuart um conjunto de acontecimentos vivenciáveis, ainda que de modo enviesado, através da leitura, se descola completamente da espessura do fato histórico e se torna um obstáculo à objetividade e um verniz desnecessário.

Assim, ao mesmo tempo em que o modelo rankeano assume o seu lugar nas cátedras universitárias inglesas no último quartel do século 19 - por exemplo, através de historiadores como William Stubbs ou Lord Acton (cf. WARREN, 2003, p. 23-41) - a escrita de Hume, postumamente, se divide ao meio. Denunciada em sua inconsistência interna, uma prática historiográfica surge em sua obra como uma espécie de resíduo clássico, em contraste com a radical modernidade de um estilo filosófico inaugural. A sua História da Inglaterra, que antes havia encontrado um público leitor tão numeroso como poucos autores o teriam, permanecerá virtualmente esquecida por um longo período². Esse silêncio, que paga o preço cobrado pela circunscrição do pensamento de Hume a um âmbito capaz de legitimar a sua própria autonomia - uma filosofia, tomada, enfim, em seu sentido mais fundamental - talvez seja, ironicamente, o resultado de uma condição histórica. É essa condição que pretende fazer de textos como o Tratado da natureza humana portadores de uma modernidade que o uniria, imediatamente, por exemplo, à Crítica da razão pura ou, o que é ainda mais anacrônico, ao Nascimento da tragédia ${ }^{3}$. É, também,

2 Dentre as noventa edições em língua inglesa da obra, desde a publicação original do primeiro volume até hoje, somente três apareceram no século 20. Cf. FIESER, J., 2003, p. 27-40. Se já não fosse automaticamente evidente para os leitores de Hume, uma análise da bibliografia especializada não deixaria dúvidas quanto ao fato de que a História continua, apesar de relevantes esforços, ocupando um lugar menor no corpus humeano.

3 No primeiro caso, a tradição se consolidou mais rapidamente, sobretudo a partir das análises - sem dúvida interessantes - de Kemp-Smith (1915; 1941) e se estendendo a Lewis Beck (1978) ou Michel Malherbe (1993). Sobre Nietzsche e Hume, as conexões são mais ocasionais, mas um artigo publicado mais recentemente na Hume Studies é representativo dessa leitura (cf. BEAM, 1996). Todos esses textos se caracterizam pelo projeto de uma apresentação global dos autores tratados, e, não por acaso, em nenhuma dessas obras encontramos qualquer referência, direta ou indireta, à História da Inglaterra. Em outro lugar, Malherbe (1992, p. 251-260) a menciona brevemente. 
desde essa condição, que Michel Foucault chamaria de epistemológica, que ainda se quer encontrar em Hume aquilo que quase nunca se supõe que possa não estar lá: subjetividade, psicologia, história universal, dialética. As modificações e separações que tais ideias introduzem no texto de Hume podem ser interessantes porque são as condições sob as quais nós ainda podemos constituir, nele, uma singularidade; mas, ao mesmo tempo, representam um entrave aos que, sem grande apreço pelo singular, estão mais interessados em uma posição geral que ele ocuparia em um contexto intelectual mais amplo.

É claro que não foi o século 20 que identificou o traço original do pensamento de Hume. Praticamente todas as (escassas) resenhas que surgiram por ocasião da primeira publicação do Tratado já assinalavam isso. Mas, o fundamental, aqui, é que a "novidade" é, nesses textos, invariavelmente, o signo de uma deficiência - seja por oposição à tradição à qual ele teria de se filiar, caso fosse coerente - Locke, Clarcke, Hutcheson, Mandeville, Butler, Shaftesbury são os nomes mais citados - seja em comparação à promessa de uma clareza cuja imaturidade presente no Tratado ainda permite apenas adiar. Assim, por exemplo, para o primeiro resenhista do livro de Hume, que publica uma longa, irônica e violenta crítica no jornal The History of the Works of the Learned, ainda no final de 1739, o fato do autor não ter atingido o grau de clareza em temas tão complexos poderia ser atribuído ao seu ímpeto juvenil (cf. FIESER, 2005b, p. 4 e 40). Cerca de um mês depois, outro resenhista, dessa vez na Gottingischen Zeitungen, associa aos "pensamentos peculiares" do autor o seu "grande talento para obscurecer o que outros teriam dito claramente sobre aqueles assuntos" (idem, p. 43). Por fim, um terceiro, na edição de abril-junho de 1740 da Bibliothèque raisonné des ouvrages des savant de l'Europe, inicia a sua resenha apontando o quanto o Tratado parece integrar o mesmo "projeto" de uma então recente reflexão filosófica na Grã-Bretanha, mas a sua tentativa de se colocar sobre um caminho novo poria em risco todo o rigor de suas investigações, de tal modo que "o mérito da singularidade" acabaria por degenerar no uso de uma "linguagem dificilmente inteligível" (idem, p. 49-50). É somente com a publicação de seus escristos ensaísticos e sua História da Inglaterra que Hume encontrará o reconhecimento de sua originalidade como algo positivo, como apontam a resenha dos Political Discourses na Monthly Review, em 1752 (cf. FIESER, 2005a, p. 36), e a do primeiro volume de The History of Great Britain, em 1755 na Gottingische Anzeigen (cf. FIESER, 2005c, p. 22-23). O mais importante a ser notado aqui, com tudo isso, é que, se o século 20 procurou inverter o ajuizamento dos contemporâneos de Hume, isso frequentemente se deu em função de uma ideia sobre a história, que nos colocaria em uma 
posição de onde enxergaríamos melhor as amplas consequências da reflexão do Tratado. Este artigo gostaria de exercitar a leitura na direção oposta. Talvez, com isso, tenhamos de abrir mão da singularidade da obra ou do autor, e mostrar que, lá onde se enxerga uma homogeneidade, teríamos de conduzir o olhar à sua dispersão, para, só assim, descobrir uma unidade em outra parte - e com outras características. Mas, não é essa, aliás, e aqui apenas coincidentemente, a lição que nos ensinaria o Tratado, caso ele se pretendesse ensinar algo? A condição epistemológica que nos faz descobrir um sujeito inovador ou nos faz exigir uma história metodologicamente sólida em Hume não pode, ela mesma, de dentro de seu quadro axiomático, encontrar um caminho para relativizar as suas ideias?

\section{Hume, historiador}

É importante assinalar essa condição epistemológica porque ela parece se manifestar, em maior ou menor medida, mesmo nas tentativas iniciais de retomar a importância da história no pensamento de Hume. Aquela que pode ser considerada a primeira dessas tentativas, a que George Sabine empreende em seu artigo "Hume's Contribution to the Historical Method", ainda em 1906, é um exemplo claro disso. Sabine opõe a "fraqueza dos historiadores do século 18" ao único método capaz de tornar inteligível o desenvolvimento da história, aquele que é veiculado no "despertar de Leopold von Ranke" (SABINE, 1906, p. 34). Através de uma reflexão que impõe o "método evolucionário" (idem, p. 17) como critério de avaliação do sucesso historiográfico, Sabine só pôde mesmo chegar à conclusão que, peremptoriamente, encerra seu texto:

Para um historiador, um indivíduo deve ser uma personalidade, não uma exemplificação de leis psicológicas. Hume, portanto, nunca atingiu a concepção plena de continuidade histórica através da qual os historiadores, mais tarde, aprenderam a conceber eventos como momentos de uma unidade orgânica evolutiva, e que tornou a história uma disciplina auto-suficiente, digna de estudo por si mesma (SABINE, 1906, p. 38).

Ao introduzir um vocabulário positivista que serve, ao mesmo tempo, de medida de análise, Sabine se inscreve nos limites do que Ernest Mossner denominou, a meu ver, adequadamente, de romantismo, e só pôde obter uma separação entre história e filosofia por meio de um artifício ideológico ${ }^{4}$. A crítica rankeana a que ele submete a História da Inglaterra

4 Cf. MOSSNER, 1941a, p. 659. Mossner, conhecido, sobretudo, pela sua biografia de Hume, é uma das raras exceções, na primeira metade do século 20 , no que se refere ao tratamento dado 
acaba por instituir um modelo heurístico para uma forma de narrativa que Hume não pensava como um campo autônomo do conhecimento. Tal como Ranke, Sabine reconhece os avanços obtidos pelo empirismo humeano, que recusaria análises lógicas em nome de um "método genético real" (SABINE, 1906, p. 26), a ponto de se destacar entre os seus contemporâneos. Um reconhecimento que é, frequentemente, concedido aos textos filosóficos, ou, mais precisamente, no caso de Sabine, a The Natural History of Religion. Mas, ainda como Ranke, no entanto, ele encontra, quase condescendentemente, em sua obra "estritamente histórica", as mesmas faltas dos historiadores da época (idem, p. 25-26).

É claro que, se insistimos em uma continuidade entre história e filosofia, isso não quer dizer que ela se dê em todos os níveis narrativos. Hume concebia explicitamente diferenças específicas entre os seus textos, mas é preciso identificar sob que aspectos elas poderiam se revelar. Assim, se, por um lado, em sua breve autobiografia, ele parece distinguir os seus escritos "históricos, filosóficos ou literários" (My Own Life, in: Essays, p. XXXVI) ${ }^{5}$, por outro, a Introdução do Tratado nos autoriza a reconduzir essa distinção a um nível onde ela se defaz e que se identifica, nesse último texto, como o da "ciência do homem" (cf. T, Introdução, p. 7) ${ }^{6}$. É ainda de acordo com tal heteronomia que o volume da História da Inglaterra, publicado, inicialmente, como o quinto, em 1762, e reordenado como primeiro, dois anos depois (cf. TODD, 1983, p. XX-XXIII), duplica a posição do ensaio Of the Study of History, de modo que toda a justificação da história se constrói, também aí, exclusivamente sob o signo da curiosidade e do divertimento (cf. HE I, I, p. 3-4). A prerrogativa da obra, portanto, indica, sem dúvida, uma dependência, mas que em nada ameaça a sua legitimidade, a não ser que se eleja o conjunto de premissas do final do século 19 como a única forma legítima de se empreender uma narrativa histórica.

As críticas de Sabine a Hume, no entanto, se apoiam em uma questão mais fundamental, ou antes, em uma noção de natureza humana capaz

à relação entre história e filosofia em seu pensamento, propondo uma indissoçiação radical de ambas. É interessante que Mossner, como professor de literatura, ocupe uma posição metodológica igualmente distante das prerrogativas da história e da filosofia e possa olhar para elas com uma espécie de filtro sintético.

5 Ou ainda: em carta a William Mure of Caldwell, em outubro de 1754, Hume afirma que, se os seus esforços para atingir as "qualidades primeiras" de um historiador - imparcialidade e capacidade de despertar interesse - não tivessem tido resultado aos olhos de seu correspondente, ele estaria pronto para "queimar todos os papéis e voltar para a filosofia" (Letters, I, p. 210).

6 A relação entre a ciência do homem e "as outras ciências" é dupla. Elas se separam no que diz respeito aos seus objetos - considerados como já constituídos -, mas as últimas dependem da primeira como "fundação" (T., Introdução, p. 7), na medida em que se considera a perspectiva de onde esses objetos são visados. Volto à questão da perspectiva mais adiante. 
de revelar as inexatidões e as lacunas do projeto de sua História. Ela também se apresenta no parágrafo que conclui o artigo de 1906:

Hume introduziu um método de explicação psicológica que encontrava as reais forças motrizes da natureza humana nas paixões. Na medida, entretanto, em que ele concebia o indivíduo como composto de princípios psíquicos imutáveis e atômicos, ele pensou que o estudo da história deveria ser direcionado, em última análise, para a descoberta e elucidação das leis psicológicas universais. [...] Hume fez uma contribuição de grande importância para o método histórico, ainda que indireta. Mesmo assim, ele ignorou o ponto de vista essencialmente histórico porque foi levado a negligenciar o aspecto único e individual dos eventos históricos e das pessoas (SABINE, 1906, p. 38).

Dito de outra forma, o equívoco metodológico da História da Inglaterra se apoiaria em um equívoco anterior, antropológico, constituído no Tratado. Compreender a relação entre natureza humana e ciência, desse modo, significa, para Sabine, recusar o modelo epistemológico descritivo e "estático" (que limita o espectro do psicológico) em nome de um modelo psicologizante (que procederia de modo exatamente contrário) e que seria o único a permitir a passagem consequente do ceticismo filosófico ao romantismo histórico ou, pura e simplesmente, da filosofia à história.

De fato, a posição de Sabine, que já aparecia como inadequada a Mossner, na década de 1940, hoje em dia se impõe com ainda menos vigor. Uma crítica já suficientemente sólida da distinção operada pelos comentadores entre um Hume cético e um Hume naturalista se apresenta como uma leitura alternativa mais atenta aos desníveis que se alternam durante todo o percurso que liga o Tratado à História ${ }^{7}$. Mas o que ela aponta, para além disso, é como a passagem entre essas duas narrativas depende de uma definição precisa da natureza humana em Hume. Evidentemente, nem todos os leitores de seu primeiro livro se interessaram pelos seus escritos históricos, assim como nem todos os que se voltaram para esses tentaram encontrar uma linha qualquer que os guiasse até o primeiro. O que é muito significativo, no entanto, é o fato de que, ao longo do século 20 - especialmente, mas não exclusivamente, em sua segunda metade ${ }^{8}$-, aqueles que procuraram comparar os dois textos, aproximando-os ou afastando-os, frequentemente recorreram

7 Cf. RUSSELL, 1995, p. 71-84. No entanto, a publicação das palestras de P. F. Strawson ministradas em 1983 sob o título Skepticism and Naturalism, assim como o seu livro anterior, Freedom and Resentment, de 1978, retomam e radicalizam essa distinção (cf. STRAWSON, 2008a, p. 54-55 e 2008b, p. 11-15).

8 Para um sumário dos textos de especialistas que, entre 1900 e 1940, se ocuparam da História da Inglaterra como parte do projeto de Hume, cf. MOSSNER, 1941a, p. 657-658. Para uma lista recente dos principais comentários, cf. referência in: PHILLIPS, 2011, p. 420-422. 
a uma avaliação da solidez dos nexos de continuidade entre natureza humana e narratividade histórica. Quanto a esse ponto, o tratamento que se dá é totalmente coerente: qualquer avaliação realmente ampla do projeto de escrita de Hume deve considerar esses nexos.

Parece ser esse tratamento, aliás, a perspectiva dominante dada ao tema, pelo menos desde a importante publicação, em 1965, da coletânea David Hume: Philosophical Historian, organizada por David Fate Norton e Richard Popkin. O alcance das investigações desenvolvidas nesse livro, no entanto, ainda se mantinha limitado por certas teses que, mesmo que de modo muito geral, reverberavam uma posição próxima àquela de Sabine. Os textos de Norton, por exemplo, apesar de reivindicar, explícita e enfaticamente, a pertinência ampla da dimensão histórica desde o Tratado, identifica a escrita historiográfica como um novo caminho no pensamento de Hume, ao mesmo tempo como síntese e como ruptura em relação ao projeto inicial. Para Norton, o ceticismo dos primeiros escritos teria levado necessariamente ao problema da contingência social dos juízos científicos e, em especial, dos juízos morais, fazendo com que a abordagem dos processos de formação dos princípios gerais da ciência da natureza humana tivesse de se deslocar para o plano político e, mais fundamentalmente, para o nível histórico, onde a própria política se constituiria como tal ${ }^{9}$. A importância da História residiria, assim, na discussão em torno da legitimidade das fontes que ela teria de articular, que traduziria, em nível adequadamente social, o modelo de construção de premissas científicas inicialmente abordado no Tratado. No entanto, uma vez tendo redirecionado a reflexão acerca das leis morais para o seu meio próprio, Hume teria, segundo Norton, encontrado na História os mesmos problemas que as suas primeiras obras: a radicalidade do ceticismo que comporia a sua ciência da natureza humana teria de solapar qualquer possibilidade de um fundamento último para as leis científicas, mesmo (e, talvez, mais incisivamente) que o solo onde tal fundação se apóia fosse o da dimensão sócio-histórica (cf. NORTON, 1965, p. XLIV). Unidos, antes, de modo indissociável (cf. NORTON, 1965, p. XLIX), pelas suas deficiências, a História e o Tratado partilhariam a mesma impossibilidade de uma adequada fundamentação antropológica, ora como objeto, ora como método. Vista sob esse ângulo, a abordagem de Norton ainda duplicaria a de Sabine e de toda uma geração - que integraria, além disso, embora não para os especialistas mais recentes, a influente leitura de R. G. Collingwood ${ }^{10}$.

9 Uma hipótese semelhante é sustentada por Noxon, 1973, p. 24, quando fala de uma "metamorfose do psicólogo experimental em historiador filosófico".

10 Cf. COLLINGWOOD, 1956, p. 75-76. Como Norton, Collingwood reconhece a importância implícita da história em toda a obra de Hume. A sua crítica parece, além disso, antecipar 
Mesmo boa parte dos autores que, entre os anos de 1970 e 1980, se esforçaram para assinalar ou relativizar a continuidade positiva da narrativa histórica ao longo da obra de Hume teve de lidar com a questão do sentido metodológico da natureza humana em textos como o Tratado ou a primeira Investigação ${ }^{11}$. Em resumo, de uma maneira ou de outra, tanto os que procuraram defender quanto os que procuraram dispensar a dignidade da reflexão histórica em Hume, acabaram por encontrar o difícil desafio da compatibilização entre antropologia e narratividade. Esse desafio parece ainda mais intangível na medida em que lá onde a nossa sensibilidade histórica, mais ou menos tomada pelo modelo rankeano, procurou farejar os indícios de sua longínqua origem, o texto de Hume decepciona: ao invés de abrir as portas para a diferença do tempo, ele conduz, insistentemente, ao enclausuramento do mesmo. A passagem mais significativa, nesse sentido, é aquela que encontramos na primeira Investigação. A sua importância nos permite citá-la mais longamente:

É universalmente reconhecido que há uma grande uniformidade entre as ações dos homens, em todas as nações e em todas as eras, e que a natureza humana permanece ainda a mesma em seus princípios e operações. Os mesmos motivos sempre produzem as mesmas ações: os mesmos eventos se seguem das mesmas causas. Ambição, avareza, amor-próprio, vaidade, amizade, generosidade, espírito público: essas paixões, misturadas em vários graus, e distribuídas pela sociedade,

alguns aspectos gerias da posição de Norton: "Hume permaneceu inconsciente do impacto total de sua filosofia sobre a história e, como escritor de história, ele se enquadra entre os homens do Iluminismo, impedido, como eles, de uma história científica por uma visão de natureza humana substancialista que era bastante inconsistente em relação aos seus princípios filosóficos" (ibid., p. 76). Sobre a leitura de Collingwood, cf. WERTZ, 1994.

11 Seria inapropriado tentar, aqui, uma revisão bibliográfica suficientemente ampla acerca do tema. Além dos nomes citados ao longo desse artigo, duas outras abordagens são dignas de nota. A primeira é a de Spencer K. Wertz, que, em seu livro Between Hume's Philosophy and History, reunindo ensaios publicados entre 1975 e 1996, chama a atenção para o modo como os juízos históricos retomam o procedimento de construção dos juízos causais (cf. WERTZ, 2000, p. 16). Diferentemente de Norton, entretanto, Wertz procura ver na redação da História da Inglaterra não a ruptura de um novo caminho, condenado ao fracasso, mas a radicalização da perspectiva do Tratado, resultando em um alargamento da própria noção de experiência: "História escrita e história vivida são, essencialmente, a mesma coisa para Hume" (WERTZ, 2000, p. 116). A segunda, mais infleunte, é a de Duncan Forbes, em seu livro Hume's Philosophical Politics, de 1975. Contra os que enxergaram em Hume uma psicologia naturalista, Forbes argumente a favor da distinção entre a investigação do psicólogo e a do historiador (cf. FORBES, 1975, p. 112). Somente nesse último a natureza humana alcançaria o seu nível descritivo e mais adequado à definição desenvolvida anteriormente no Tratado. Forbes explora, em outro lugar, as consequências desse abismo metodológico, chegando a afirmar que Hume não podia ser um "philosophical historian" em sentido amplo (cf. FORBES, 1977, p. 42). É interessante notar que, tanto Wertz quanto Forbes, são levados a discutir, em seus argumentos, o mesmo ponto: a tensão entre a natureza humana e o devir histórico (cf. WERTZ, 2000, p. 33-34; FORBES, 1975, p. 109-111). 
têm sido, desde o começo do mundo, e ainda são, a fonte de todas as ações e empreendimentos que têm sido observados entre a humanidade. Queres saber os sentimentos [sentiments], as inclinações e o curso da vida dos gregos e dos romanos? Estuda bem o temperamento e as ações do francês e do inglês: não podes estar muito enganado ao transferir àquele primeiro a maior parte das observações que fizeste em relação ao último. A humanidade é tanto a mesma, em todos os tempos e lugares, que a história não nos informa nada de novo ou estranho quanto a isso. O seu principal uso é somente para descobrir os princípios universais e constantes da natureza humana, ao mostrar homens em todas as variedades de circunstâncias e situações, e nos fornecendo materiais dos quais podemos formar as nossas observações e nos tornar familiarizados com os móveis regulares da ação e do comportamento humanos. Esses registros de guerras, intrigas e revoluções são coleções de experimentos, através dos quais o filósofo político ou moral estabelece os princípios de sua ciência, da mesma maneira que o físico é introduzido à natureza das plantas, dos minerais e de outros objetos externos pelos experimentos que ele faz a respeito delas. Nem a terra, a água e os outros elementos, examinados por Aristóteles e Hipócrates, são tão semelhantes quanto aqueles que, no momento, estão sob a nossa observação, quanto os homens descritos por Políbio e Tácito o são para aqueles que agora governam o mundo. [...] E se quisermos demolir qualquer falsificação na história, não podemos fazer uso de argumento mais convincente que provar que as ações atribuídas a uma pessoa qualquer são diretamente contrárias ao curso da natureza, e que nenhum motivo humano, em tais circunstâncias, poderia induzi-la a tal conduta [...]. Reconhecemos uma uniformidade nos motivos e nas ações humanas tão pronta e universalmente quanto nas operações do corpo $(E H U$ 8,7).

A grande dificuldade dessa passagem - aquela experimentada pelos autores que citamos até aqui - reside, justamente, na articulação de dois níveis, que não param de se deslocar um sobre o outro. Por um lado, o estabelecimento dos princípios gerais da ciência do ser humano depende de uma metodologia narrativa que Hume chama, adequadamente, de história. De outro, o próprio critério de verificação e, portanto, de estabelecimento, dos princípios narrativos depende de uma definição de natureza humana que passa a lhe servir de divisa metodológica. O que aqui representa, aparentemente, uma circularidade lógica pode ser lido, contudo, de outro modo, positivamente. Ou seja: o que as inúmeras "coleções de experimentos" revelam é que o seu objeto, a natureza humana, precipitado ao fundo dos conjuntos de narrativas históricas, em certo nível, também pode ser compreendido como uma narrativa de tipo particular - uma narrativa que é condição epistemológica de todas as outras. 
Um primeiro estranhamento se produz, imediatamente, aqui: afinal, como compreender essa representação da narrativa como não fundada? Ou melhor, como compreender que a sua fundação é, ela mesma, uma representação narrativa? Aqui poderia se sugerir uma solução de tipo naturalista ou fundacionalista, mas ela não poderia, justamente, dar conta da complexidade dinâmica dos níveis envolvidos na passagem citada. Análises como as de Sabine ou Norton parecem querer romper com o círculo lógico impondo-lhe um fim, um fundamento, diante do qual toda forma de narratividade funcionaria simplesmente através de uma relação de correspondência. Essas leituras precisam não apenas escavar as entrelinhas da passagem citada em busca de algum resíduo de fundação - no sentido kantiano-rankeano -, mas, em função disso, considerar todo movimento de sobreposição entre narrativa e natureza humana como inadequado. Para não condenarmos simplesmente o projeto humeano ao fracasso, como Sabine ou Norton, ou para não dividirmos Hume em dois no interior desse projeto, como Strawson, e, enfim, para não termos de buscar refúgio em um Hume "pós-moderno" como Parusnikova (cf. PARUSNIKOVA, 1993), talvez tenhamos de dar maior mérito ao procedimento historiográfico do século 18.

Dois dispositivos de análise poderiam se impôr aqui como alternativa, portanto: em primeiro lugar, recuperar o estatuto da natureza humana desde essa síntese infinita que estabelece uma relação circular entre a representação e os procedimentos representativos da identidade, entendendo o projeto de Hume como um projeto de projeto. Em segundo lugar, reinserir o modelo narrativo da obra de Hume no horizonte histórico que lhe é próprio - o que significa abandonar a urgência fundacionalista na direção de uma escrita do estilo, própria de autores que lhe eram contemporâneos, como Catharine Macauley, Rapin de Thoyras, Voltaire, Edward Gibbon, e que o reconhecerem como um historiador, dialogando diretamente com ele. Essa dissolução da singularidade da escrita de Hume nos permitiria ver como a ausência incontornável de um sujeito de conhecimento no Tratado, bem como de uma razão histórica na História da Inglaterra, dá lugar a um procedimento experimental, uma "tentativa" (attempt), como informa o título mesmo do primeiro livro, que revela que toda identificação de um objeto da ciência, observado pelo rigor empirista, nada mais é senão o processo de construção desse objeto, a sua narração. $O$ que significa que o procedimento deve ser levado ao encontro de si mesmo, e que a natureza humana é observada desde a natureza humana. O objeto do Tratado, portanto, sendo a natureza humana, de um certo nível, também é o próprio nível narrativo do Tratado. Do mesmo modo, a História da Inglaterra é, fundamentalmente, a História da natureza humana e, portanto, um outro Tratado. 


\section{Narratividade e filosofia}

Não se quer dizer, com isso, que se trata do mesmo livro, duplicado, retomado ou desdobrado. Mas, quer-se dizer que o procedimento narrativo histórico articulado em 1754 já estava em funcionamento em 1737 - ou, mais, havia sido a própria descoberta do Tratado: a de que todos os juízos são, em função da posição incontornável do empirismo, históricos. A fórmula de Deleuze para definir o procedimento desse último livro é bastante útil aqui: que um espírito ou uma mente se torne uma natureza humana parece ser, sob essa perspectiva, o seu problema central ${ }^{12}$. É preciso, portanto, constituir a investigação histórica antes de se levar adiante a psicológica (cf. DELEUZE, 1993, p. 2). Mas, a natureza humana pode ser reconduzida ao seu tornar-se não somente em meio a uma investigação sobre a mente, que, originalmente, ou pré-identitariamente, nada mais é senão o plano passivo de associações de intensidades qualitativas ${ }^{13}$, mas em um plano que lhe é análogo, o dos costumes e do senso comum. Análogo na medida em que, em ambos, as identidades articuladas nos juízos erguidos no interior das hipóteses científicas são reconduzidas, retrospectivamente, ao seu devir.

Assim, o Tratado já nos informava, por exemplo, que o objeto eu, que integraria a pergunta "o que é uma identidade pessoal?", nada mais seria que o efeito de um processo de estabilização "ao longo de uma suposta variação de tempo" ( $T$, 1.4.6.6). Com isso, ele pôde afastar a inconveniente e delirante presença do metafísico que confessava perceber uma impressão da identidade onde havia apenas o devir das impressões. Do ponto de vista historiográfico, esse tratamento também teve consequências que distanciaram Hume da tradição clássica, especialmente daquela formada pelos historiadores de tendência whig. Entre esses últimos, a ideia comumente partilhada era a de que o regime monárquio dos Stuart havia sido uma abominação, porque ia de encontro

12 Cf. DELEUZE, 1993, p. 2. O estudo de Deleuze é admirável por vários motivos, entre eles, pela data de seu aparecimento, em 1953, quando as discussões em torno da obra de Hume tomavam uma direção nitidamente naturalista. No entanto, o uso de categorias de análise como psicologia, cultura, sociologia, sujeito, tal como operado em seu comentário, me parece um pouco abusivo, se o observo de minha posição historiográfica. Isso, no entanto, não reduz em nada o seu mérito, e é surpreendente que Deleuze continue sendo amplamente ignorado pela grande maioria dos especialistas em Hume de língua inglesa.

13 Cf. DELEUZE, 1993, p. 8: "Quando Hume fala de um ato do espírito, de uma tendência, não quer dizer que o espírito seja ativo, mas que ele é ativado, tornado sujeito. O paradoxo coerente da filosofia de Hume é o de apresentar uma subjetividade que se ultrapassa e não é, por isso, menos passiva. A subjetividade é determinada como um efeito, é uma impressão de reflexão. O espírito se torna sujeito ao ser afetado pelos princípios". E, ainda, T 1.4.6.4: "A mente é um tipo de teatro, onde várias percepções sucessivamente fazem a sua aparição; passam, repassam, se deslocam e se combinam em uma variedade infinita de posturas e situações [postures and situations]". 
ao fundamento da liberdade individual, garantido desde sempre em função de uma legislação constitucional primitiva, que estaria na origem da sociedade britânica e institucionalizado da forma mais perfeita com o parlamentarismo que teve lugar após a Revolução Gloriosa. Muito já se falou, também, a respeito da posição tory de Hume apresentada na História da Inglaterra, de sua defesa dos Stuart e de sua crítica ao republicanismo e à Reforma Protestante ${ }^{14}$ - e ele mesmo, em alguns lugares, confirmou essa confissão política ${ }^{15}$. Porém, ela também pode ser entendida, de modo mais amplo, na direção contrária: como uma confissão metodológica, uma recusa de admitir a ligação homogênea entre um fundamento original e um juízo histórico. Contra historiadores como Rapin de Thoyras ${ }^{16}$, Hume recusou o modelo contratualista, porque a sua História mantinha o procedimento analítico do Tratado; em outras palavras, continuava rejeitando as ideias de fundamento último e de continuidade epistemológica. Assim, o seu texto podia, ao mesmo tempo, reconhecer a liberdade de seu próprio tempo, mas denunciar as restrições e a violência impostas em sua emergência durante os atos que se seguiram a 1688 ( $H E$ V, Apêndice IV, p. 125), admitir as qualidades pessoais dos indivíduos religiosos, mas condenar a origem de todas as

${ }_{14}$ Há algumas décadas, os comentadores de Hume tentam relativizar ou mesmo inverter as declarações explícitas que ele fez a favor da política Tory, com maior ou menor sucesso. Raras são as interpretações que identificam esse favorecimento como dominante, sendo GRENE, 1941, e TREVOR-ROPER, 1966, duas notáveis exceções. A posição majoritária é a de que, apesar dessas declarações, Hume seria, fundamentalmente, um Whig - cf. a leitura de FORBES, 1977, p. 44 - também sobre esse ponto muito influente - e de CONIFF, 1978-1979; mais recentemente, as de PHILLIPS, 2000, p. 37; WOOTON, 2009, passim; MOSSNER, 1941b, passim, e RADCLIFFE, 2011, p. 15, procuram relativizar mais amplamente a confissão política humeana. Sobre a relação entre historiografia e política partidária na Grã-Bretanha à época de Hume, cf. HICKS, 1987, e KIDD, 1993.

15 A afirmação mais conhecida é aquela de My Own Life, que trata das correções anti-Whig da História da Inglaterra: "Mas, apesar de ter sido ensinado pela experiência que o partido Whig detinha o uso de todos os lugares, tanto no Estado, quanto na literatura, estava tão pouco inclinado a servir a seu clamor sem sentido que, em mais de cem alterações, que o estudo e a leitura mais aprofundados ou a reflexão me levaram a fazer nos dois primeiros [violumes sobre] os Stuart, eu os fiz invariavelmente em favor da posição Tory"(My Own Life, in: Essays, p. XXXVIII). Um exemplo desse tipo de revisão é a que retira, nas edições posteriores a 1770 da História da Inglaterra, a palavra "feliz" na frase "este governo singular e feliz de que dispomos no presente" (cf. TREVOR-ROPER, 1964, p. 388), como referência ao republicanismo que the era contemporâneo. Durante a década de 1750, Hume parece procurar se manter igualmente distante do partidarismo Whig e Tory (cf. Letters I, p. 167, 180, 196), mas essa posição se modifica entre as décadas de 1760 e 1770, quando uma postura mais explicitamente Whig vem à tona (cf. Letters I, p. 379; II, p. 216, 242, 409). Ainda assim, algumas passagens de sua correspondência permitem ao menos relativizar essa adesão, o que resulta em um debate infinito entre os comentadores.

16 Sobre Paul Rapin de Thoyras e a sua posição na historiografia, cf. OKIE, 1991, p. 47-73. Em carta de 22 de julho de 1757 a Le Blanc, Hume confessa que, apesar de inicialmente ter se deixado levar pelo reconhecimento de Thoyras no meio intelectual, após examiná-lo com cuidado, chegou à conclusão de que ele era "completamente desprezível" (Letters I, p. 258). 
religiões, constituídas, de início, pelo "mais baixo vulgo" (HE VI, LXII, p. 142). O caminho que a ausência irrevogável de um fundamento último para a identidade abre para Hume não é simplesmente o da conformação a um fundamento parcial, mas, bem mais que isso, o deslocamento para a questão sobre os processos de formação das identidades e dos juízos ${ }^{17}$.

Nesse processo, que resulta na homogenização das sucessões de impressões, objetos como a identidade pessoal, o governo da GrãBretanha, a liberdade de imprensa, assim como o ajuizamento da beleza ou a apologia do suicídio, não podem ser deduzidos de um elemento universal que lhes antecederia - algo como a bondade de Deus, a atividade da mente ou o progresso da história. Eles são reinseridos na heterogeneidade da cadeia de impressões e nos mecanismos sociais que, estabilizando a diferença entre os elos dessa cadeia, produz cada um desses objetos. O ensaio "Of the Original Contract", que aparece na terceira edição de Essays, Moral and Political, em 1748, é um ataque frontal contra a tese whig de uma constituição primitiva e de um suposto estado de natureza que lhe antecederia. Ele reverberará em muitas passagens da segunda Investigação (por exemplo, em EPM III, p. 87-88), assim como o ensaio sobre o suicídio, contra a tese que o condena em função de sua negação da vontade de Deus como fundamento último, afirma: "Pergunto por que concluis que a Providência me colocou nessa posição [station]? De minha parte, descubro que devo o meu nascimento a uma longa cadeia de causas, das quais muitas, e mesmo a principal, dependeram das ações voluntárias dos homens" (Essays, p. 585).

Essa caracterização excessivamente geral do método experimental de Hume não pode, certamente, nos levar a crer que não existam diferenças

17 Utilizo aqui a denominação identidade para me referir, de maneira muito ampla, ao processo de construção de objetos regulares na mente, até certo ponto indiferente à distinção promovida por Hume entre identidade numérica e específica ( $T$ 1.4.6.13). Quaisquer que sejam os conteúdos que formam uma unidade - uma ideia geral como igreja ou particular como este ruído -, o seu processo de formação, sob um ponto de vista geral, obedece ao mesmo procedimento: hipostasiação de uma cadeia de impressões sucessivas sob a forma de uma estabilização. Sob esse aspecto, podemos afirmar das identidades em geral aquilo que Hume afirmava em relação às identidades específicas: "O nosso principal interesse, assim, deve ser provar que todos os objetos a que atribuímos identidade sem observar a sua invariabilidade e ininterrupção são de tal modo que consistem em uma sucessão de objetos relacionados" ( $T$ 1.4.6.7). Quanto ao uso do termo "juízo" (judgment), é preciso relativizar a sua importância para Hume. A nota ao final de T 1.3.7.5 elimina, contra a tradição escolástica, qualquer distinção ou prioridade epistêmica entre concepção, juízo e raciocínio, mas o ensaio "Of the Standard of Taste" parece fazer um uso mais restrito do termo (cf. Essays, especialmente p. 234-237). Na História da Inglaterra, juízo corresponde, na maior parte das vezes, a bom senso - por exemplo, quando relata a recuperação do "juízo moderado" (cool judgment) do Visconde de Northumbria diante da possibilidade de um golpe contra o Rei Guilherme I (cf. HE I, p. 212). Todos esses matizes estão presentes no uso da palavra, mas, ao utilizá-la, gostaria de chamar a atenção para o modo como as conexões entre as identidades resultam de um processo. 
importantes entre juízo causal, juízo histórico, juízo de gosto, identidade pessoal, etc. Mas, o que, no entanto, ela permite enxergar é justamente a síntese final do experimento. Como todo experimento levado adiante no campo da filosofia natural dos séculos 17-18 - onde Hume procura colher os signos de seu projeto filosófico -, a investigação parte da análise das diferenças constitutivas de um objeto para, por etapas, ascender a sínteses cada vez mais gerais. Esse, afinal, era o método amplamente divulgado entre os filósofos naturais do século 18. Com isso, não nos referimos exclusivamente a Newton - embora uma versão vulgata de seus Principia pudesse ser lida, em maior ou menor medida, nas entrelinhas das obras de tais filósofos. Um dos representantes desse método, por exemplo, era John Woodward, geólogo próximo de Newton, que, segundo Tom Beauchamp, era uma fonte disponível para as leituras científicas de Hume (cf. a nota 83, in: Diss., p. 219). No prefácio de sua obra An Attempt Towards a Natural History of the Fossils of England, de 1729, Woodward proclama explicitamente o sentido de seu método: ultrapassar a singularidade das diferenças catalogadas e divididas em classes, recolhidas através da observação, na direção da "mais alta estabilidade e demonstração" (WOODWARD, 1729, p. XII). É interessante que Hume, em uma passagem sobre a probabilidade das causas, recusando-lhes a demonstrabilidade empírica, recorre a uma definição dessa síntese como "graus de estabilidade e certeza [stability and assurance]" ( $T$ 1.3.11.9), reverberando, portanto, não tanto Newton ou um ou outro físico específico de sua escola, mas uma prerrogativa metodológica experimental suficientemente fluida a ponto de ser manipulada em muitas direções, inclusive anti-newtonianas. A infindável discussão em torno da importância da herança newtoniana no pensamento de Hume poderia, no entanto, nos levar bem mais longe do que cabe aqui ${ }^{18}$.

Esse mecanismo de estabilização de identidades conectadas e, portanto, de juízos, que atravessa tanto o Tratado quanto a História e os Ensaios, procede em três etapas bem conhecidas dos leitores de Hume. A primeira opera uma distinção metodológica entre o nível empírico das impressões que se sucedem e o nível mental onde as conexões

18 Para uma breve avaliação a respeito da bibliografia disponível, cf. FORCE, 1987. O trabalho de Eugene Sapadin (1997), M. A. Stewart (2005) e os capítulos "What did Eighteenth-Century Scottish Student Read?" e "Hume's Intellectual Development, Part II", no livro de Roger Emerson (2009), ao reconstruirem o horizonte pedagógico e intelectual da Escócia do século 18, acabam por relativizar substancialmente o papel da filosofia natural de Newton nesse contexto. De modo geral, estou convencido de que a influência da física de Newton em Hume é muito mais difusa do que normalmente se assumiu, como aponta Paul Jones. Cf. JONES, 1982, p. 11-13. As inúmeras referências ao método da filosofia natural ao longo de sua obra - por exemplo, em $T$ 1.1.4.6; $T$ 1.2.5.26 (nota); $T$ 1.3.8.8-17; bem como o elogio de Newton no último capítulo do último volume da História da Inglaterra (cf. HE VI, LXXI, p. 542) - não parecem demonstrar nenhum conhecimento específico mais aprofundado do método dos Principia. 
se produzem, a partir da constatação de que essas conexões não correspondem a nenhum dado sensível. A segunda conduz a identidade à série de sucessões temporais, verificando até que ponto elas nos fornecem material empírico para a construção de uma homogenização, e a terceira, reconhecendo os limites do segundo procedimento, se desloca para o plano onde as paixões permitem tal homogenização. É relativamente fácil distinguir o funcionamento desse esquema na seção do Tratado sobre a inferência das impressões às ideias nos juízos causais ( $T$ 1.3.6), assim como em muitas passagens do mesmo livro acerca da identidade pessoal (por exemplo, $T$ 1.4.6.16) e na descrição da formação do juízo de gosto delicado no ensaio "Of the Standard of Taste" (cf. Essays, p. 241). No entanto, pouca atenção tem sido dada ao processo de formação dos juízos históricos - ou, nos termos de Hume, à composição das narrativas. Com a notável exceção de Nicholas Capaldi (cf. CAPALDI, 1995, originalmente publicado em 1978, p. 3-23), a relação entre narratividade histórica e causalidade, do ponto de vista das conexões que as tornam possíveis, tem sido, praticamente, deixada de lado. Isso é surpreendente, especialmente se olharmos com atenção a grande quantidade de passagens onde narrativas históricas se apresentam como "exemplos" ou "instanciações" das relações ou conexões descritas no Tratado. Na verdade, do ponto de vista do método experimental de Hume, não-fundacionalista, "exemplos" podem ser computados como partilhando do mesmo estatuto epistêmico que os objetos mentais, que instanciariam as mesmas regras gerais de estabilização - o que garante a essas narrativas uma importância ainda maior. Não foi, absolutamente, por acaso que Hume tenha sido levado a discutir a coerência das formas de narração justamente no momento em que discute a questão da associação de ideias na primeira Investigação: assim, "na composição de narrativas, os eventos ou ações que o escritor relata devem ser conectados por algum vínculo ou ligação", formando um "plano ou visão" unívocos $(E H U 3,6)$. Contudo, é a passagem três parágrafos adiante que torna a relação entre juízos históricos e causalidade mais que uma mera analogia:

Mas, a espécie mais comum de conexões entre os diferentes eventos que entram em qualquer composição de narrativa é o da causa e efeito; enquanto os historiadores traçam a série de ações de acordo com a sua ordem natural, remonta a suas fontes e seus princípios secretos, e delineia as suas mais remotas consequências. Ele escolhe para o seu tema uma certa porção daquela grande cadeia de eventos que compõem a história da humanidade: ele se empenha em tocar em sua narrativa cada elo nessa cadeia; às vezes, uma inevitável ignorância torna todas as suas tentativas [attempts] infrutíferas; às vezes, ele suprime através da conjectura o que está faltando no conhecimento. E ele é sempre sensível 
para o fato de que, quanto menos rompida é a cadeia que ele apresenta ao seu leitor, mais perfeita é a sua produção. Ele vê que o conhecimento das causas é não apenas o mais satisfatório, sendo essa relação a mais forte de todas as outras, mas também o mais instrutivo, já que é somente pelo conhecimento que somos capazes de controlar eventos e governar a posteridade [...] (EHU 3, 9).

O que a conjectura ${ }^{19}$ do historiador promove, no nível narrativo, contra as lacunas que a ignorância impõe à cadeia dos eventos, é uma estabilização do mesmo tipo que aquela reconhecida pelo filósofo, no nível mental, a partir da crença derivada do hábito. Em ambos os casos, o procedimento analítico em três etapas está em funcionamento: distinção entre eventos e conjecturas, identificação da heterogeneidade da cadeia de eventos, estabelecimento de uma transição estável e sólida que não apenas torna possível um juízo presente, mas, pela mecânica que ela instancia, se estende em direção a juízos futuros.

Mas, mais do que reconstruir a epopéia do espírito, a transformação de uma cadeia de impressões sucessivas em uma mente que as estabiliza, a função da narrativa, no Tratado tanto quanto na História, pode ser lida em uma outra direção: ela pode indicar que a passagem de um nível ao outro não se dá a partir de um fundamento - ontológico, epistemológico, ou mesmo cosmológico. Grande parte dos comentadores de Hume acaba por optar, em alguma medida, pela fundacionalização de um desses dois níveis, como se devêssemos buscar a origem da natureza humana na heterogeneidade selvagem e caótica das impressões ou na regularidade artificial e incontornável que ela impõe a essas. Entre os primeiros, como em Sabine ou David Pears, a ênfase na heterogeneidade sublinha, irremediavelmente, o atomismo de Hume ${ }^{20}$. Entre os últimos, como parece ser o caso de Deleuze e Garrett, o natural, cuja definição última é perseguida pelo Tratado, é, antes, o conjunto limitado de princípios associativos do e no espírito. A enorme dificuldade que todos esses comentadores encontram na tentativa de sistematizar a natureza humana definida por Hume como um modelo de objetividade heterogênea ou como uma atividade espontânea do espírito parece residir justamente na própria ambiguidade do natural em seus textos. Toda a introdução do Tratado é atravessada pela dupla caracterização da natureza humana, de modo que o seu ponto de partida mesmo é a compreensão de que "nós mesmos não somos apenas os seres que

19 Sobre a conjectura de tipo causal, cf. T 1.3.11.5-8.

20 É nesse sentido, aliás, que Pears condena a teoria das ideias de Hume por não ter conduzido "a sua análise fenomenológica em um espírito mais holístico" (PEARS, 1990, p. 21). Em outro lugar, Pears já havia criticado, pelos mesmos motivos, o que chamava de "ultrasimplificação" na teoria humeana (PEARS, 1966, p. 15-16). 
raciocinam, mas também um dos objetos sobre os quais raciocinamos" ( $T$ Intr., 4).

Parte dessa dificuldade, no entanto, parece ser diluída se admitirmos duas prerrogativas de leitura do livro de Hume como projeto, como "posição" (station) ( $T$ Intr., 6). Na primeira, assumiríamos que essa ambiguidade não é ultrapassada, mas consitui justamente o modelo que permite a constituição do procedimento analítico em três etapas que definimos antes. Com isso, a ênfase é dada no mecanismo de passagem do nível dos objetos ao nível do espírito, para utilizar o termo empregado também por Deleuze. Isso se complementa com a segunda prerrogativa, segundo a qual essa passagem, assim como os níveis que ela articula, não deve ser confundida com uma origem, no sentido de uma fundação. Com isso, essa passagem não se assinalaria como o fundamento da natureza humana, mas como a sua expressão. O projeto de Hume poderia ser lido, assim, como um projeto expressionista - o experimento que o constitui, conduzido sob a forma observacionalista da física do século 18, no entanto, não se limita a ela, pois revela, a uma certa altura, que o objeto que se procura é, antes de tudo, a expressão de suas condições de objetividade. Sem um transcendental capaz de ancorar tais condições a um sujeito qualquer, tudo que resta à expressão é a sua narratividade mesma. O caminho que nos permitiria avaliar de que modo uma "natureza" seria sintetizada sob a forma de "uma" natureza só poderia ser aquele que articularia a sucessão temporal das impressões a uma narração estabilizadora sem optar por uma ou outra. Evita-se, assim, a armadilha ontológica ou epistemológica da origem. A ciência do homem do Tratado descobre como natureza a narrativa histórica da natureza: as relações causais se revelam como a estabilização de uma cadeia de impressões que se sucedem no tempo da mesma maneira que o poeta e o historiador organizam as suas narrativas. É a "força e a ordenação regrada" que, "emergindo dos costumes e da relação de causa e efeito", permite a Hume aproximar os juízos causais das narrativas dos "livros de viagem e dos historiadores"21.

Outra consequência importante sobre o estatuto da narratividade na definição de natureza humana em Hume - que tem sido amplamente negligenciada pelos comentadores - é o fato de que o predomínio da narração como matriz de inteligibilidade de todos os juízos justifica, em um nível fundamental, a indiferença promovida entre literatura, história e filosofia, ainda que, no nível da recepção de seus objetos, elas sejam

${ }^{21}$ Cf. $T$ 1.3.9.4. Em T 2.3.7.7, assim é dito sobre a conexão entre associação de ideias nos juízos causais e narratividade histórica: "Sempre seguimos a sucessão do tempo ao localizarmos as nossas ideias, e, da consideração de qualquer objeto, passamos mais facilmente para aquele que se segue imediatamente a ele do que para aquele que veio antes dele. Podemos aprender isso, entre outras instâncias, da ordem que sempre se observa nas narrativas históricas". 
distintas. É verdade que a primeira Investigação afirmava uma enorme variação no princípio de conexão entre os objetos em jogo nas narrativas históricas e poéticas (cf. EHU 3, 7). Mas, na mesma seção, um pouco mais à frente, Hume especifica: trata-se de "diferenças de grau", não de natureza, de modo que a distinção entre narrativas históricas e literárias se torna "difícil, se não impossível", constituindo "mais uma questão de gosto que de raciocínio" (EHU 3, 15). Da mesma forma, já no Tratado, Hume havia empreendido inúmeras aproximações entre filosofia, história e poesia, muitas vezes assinalando a gradação de vivacidade de suas narrativas como modelo de diferenciação ${ }^{22}$.

Justamente essa compreensão da história como narrativa e a heteronomia que ela implicava é que parecia inadmissível para Ranke e os seus adeptos. Os historiadores do final do século 19 eram homens nutridos pelo romantismo do fato: a história, portanto, para eles, devia se ocupar em reconstruir um mundo perdido, trazer de volta a origem social que explicaria as nossas paixões. Mas, tal busca pelos fundamentos sociais dos afetos humanos é completamente pulverizada na reflexão de Hume: as paixões são sociais não porque derivam da sociedade, mas porque a tornam possível. Por outro lado, a sociedade, considerada agora em outro nível, retoma as paixões e forma o seu padrão de comportamento moral. A mesma coisa acontece entre impressões, ideias e natureza humana no Tratado: as impressões e ideias fazem emergir uma natureza humana, mas o que o procedimento experimental do Tratado descobre é que essa natureza como estabilização dos juízos já estava em jogo na própria base do experimento, não como algo dado, mas como elemento de narratividade. Tudo isso é inadmissível para Ranke - ele precisa recusar a historiografia de Hume justamente porque ela é desprovida de objetividade científica e de fundamento moral. Circunscrita em sua narratividade, ela não pode promover o salto retrospectivo, rumo a uma natureza que só se apresenta na narrativa pela manifestação de sintomas. Ora, foi justamente essa somatização da natureza humana que Hume não quis operar, e talvez esse seja o ponto mais importante de sua posição: do natural ao narrativo, o humano se estende como um campo sem fronteiras, nenhuma distância hermenêutica se impõe. Como um historiador clássico, a sua obra ainda não se deixava assombrar pelo império do símbolo ${ }^{23}$.

22 É sobretudo na seção do Livro 1 sobre as influências da crença na formação dos juízos que Hume discute de que forma a vividez de uma ideia "se difunde" através da cadeia de ideias em que se inscreve, relatando o mesmo mecanismo na poesia e na filosofia, com a observação de que a primeira o opera "em um grau menor" ( $T$ 1.3.10.9-10).

${ }_{23}$ Por oposição à centralidade da narrativa em historiadores como Hume, o século 19 pode ser compreendido, portanto, como o século da história como decifração. Lionel Gossman procurou mostrar de que forma esse trabalho hermenêutico aproximava o historiador do poeta e do filósofo no século 19 (cf. GOSSMAN, 1986). 


\section{Um certo destino da narrativa humeana}

Em certa medida, Hume ainda estava vinculado a uma tradição que Popkin chamou de pirronismo histórico. Essa tradição pretendia solapar as pretensões de conhecimento das narrativas históricas apontando para a heterogeneidade dos valores morais que cada uma delas, concomitante e contraditoriamente, podia veicular ${ }^{24}$. O que o Tratado, assim como a História da Inglaterra, nos ensina, diz respeito não à veracidade dos fatos, mas à verossimilhança das narrações que os articulam. A questão da evidência histórica não havia ainda se deslocado para o centro do ofício do historiador, como ocorrerá, mais tarde, com a "virada arquivística" de Ranke (cf. ESKILDSEN, 2008.). No entanto, não podemos afirmar, inconsequentemente, que a História de Hume não se importa com a confiabilidade dos fatos que narra, mas as suas questões se inscrevem em outro cenário, que seria útil esboçar.

O universo historiográfico da segunda metade do século 18 poderia ser descrito como tensionado entre dois partidos, o de uma espécie de teoria moral da história, ocupada com o quadro geral e imutável das paixões humanas, e o da estilística narrativa. Como notou Mark Salber Phillips,

De um lado, os historiadores sustentavam uma teoria do conhecimento que exigia um grande grau de abstração: somente assim a história seria propriamente 'filosófica'. Por outro lado, eles também mantinham uma visão da narrativa que assumia que a efetividade moral da escrita histórica dependeria do poder de evocar a simpatia do leitor (PHILLIPS, 2004, p. 131).

Muitos autores - e Hume é, certamente, um deles - conjugaram esses dois modelos em seus trabalhos, distribuindo-os em dois níveis distintos ou alternando-os no corpus de suas obras. A atenção dada por eles ao aspecto geral da espécia humana, aquilo que, como vimos, Hume havia chamado a respeito da história, na primeira Investigação, de "princípios universais e constantes", lhes permitiu serem conhecidos como philosophical historians, algo que lhes atribuía uma espécie de "pedigree filosófico", para utilizar uma expressão de James Fieser (FIESER, 2007c, p. XIV), e lhes colocava acima dos outros, meros cronistas. No entanto, parece haver, de fato, para retomar a ideia de Popkin, uma espécie de cenário limítrofe na historiografia desse período. Aos poucos, a preocupação com o estabelecimento de uma

${ }^{24}$ Cf. Popkin, 1965, especialmente p. XIss. Popkin tem razão ao apontar, breve, mas enfaticamente, que Hume estaria, em relação a essa tradição, em um momento de "transição" (p. XXX), pois o seu ceticismo, diferentemente daquele dos autores protestantes no século 16-17, que formavam a base do pirronismo histórico, não servia mais para destruir a possibilidade de qualquer história, mas para legitimá-la como narrativa. 
antropologia histórica precisou buscar recursos cuja legitimidade poderia escapar à ameaça do pirronismo, ao ser comprovada universalmente, o que fez com que o tema da veracidade do testemunho histórico aparecesse no horizonte metodológico da época. Nesse momento, um debate se estabelece entre os historiadores que creditam demasiada confiança em fontes impressas e aqueles que procuraram se apoiar em material manuscrito como testemunho primário. Que essa discussão se apresenta ainda em termos muito vagos e gerais, isso se deixa entrever, por exemplo, pelo fato de que o uso técnico da palavra "fonte" [source] só foi empreendido nas últimas décadas do século 18, mais precisamente em 1777, por William Robertson (cf. BENTLEY, 1997, p. 381). Ela, entretanto, aponta para o esgotamento iminente de um paradigma narrativo que, no caso de Hume, era central para todo o seu pensamento.

Seja como for, Hume esteve, em alguma medida, ciente das opções metodológicas disponíveis em seu meio intelectual ${ }^{25}$. Não foi apenas por afinidade política, ou seja, pelo partidarismo tory, que ele havia apoiado muitas de suas observações da História da Inglaterra no estudo de Thomas Carte, General History of England. Carte, por oposição a Rapin de Thoyras, defendia o ofício do historiador como pesquisa de fontes manuscritas. O próprio Hume, no entanto, não se ocupou em rastrear ou mesmo consultar documentos originais; e o impressionante número de 30.000 livros a que ele tinha acesso, desde 1752, como Guardião da Biblioteca dos Advogados em Edimburgo, facilitava o recurso a um amplo espectro de fontes impressas ${ }^{26}$. Assim, sintomaticamente,

25 Diante delas, a sua posição assume uma coerência que a tradição que lhe seguiu não podia suspeitar: é em função do anti-fundacionalismo de sua filosofia que a sua historiografia recusa ultrapassar a narrativa como modelo metodológico, assim como, ao mesmo tempo, graças ao seu modelo de narratividade que a natureza humana se apresenta não sob a forma específica de uma antropologia, mas de uma teoria dos costumes.

${ }^{26}$ Cf. Mossner, 1980, p. 301 . O uso dessas fontes, no entanto, não pode ser considerado superficial. Isso fica claro com relação à narrativa do julgamento e da condenação de Maria Stuart no primeiro volume - agora sexto - da História da Inglaterra. Talvez esse seja, de fato, o ponto politicamente mais polêmico do livro, já que os partidários do regime whig insistiam em enxergar em toda a dinastia dos Stuart a encarnação da opressão, enquanto historiadores tory procuraram defendê-la. Por esse motivo, whigs tentaram demonstrar a culpa de Maria Stuart no assassinato de seu marido, Lorde Darnley, fundamentando a acusação na veracidade de um documento um tanto obscuro, um conjunto de cartas supostamente escritas pela rainha, onde ela teria confessado o crime. Os tories, por sua vez, desmentiram furiosamente a validade desse documento, apontando-o como forjado. A narração da condenação e morte da rainha, sob a acusação de assassinato, repousava, portanto, na questão da veracidade da fonte. Era de se esperar que Hume, em sua tendência confessadamente tory, empreeendesse uma desqualificação das cartas. O que se observou, no entanto, foi o contrário, e o Capítulo XXXIX da História apresenta uma exaustiva análise e comparação de fontes a respeito do assunto, legitimando, minunciosamente, a sua posição contra o ataque dos críticos. Isso fez com que ele conquistasse, como ele mesmo comenta em sua autobiografia, não apenas a desaprovação dos whigs, graças às observações a respeito de outros assuntos, mas, também a dos tories, graças a seu ataque contra a rainha (cf. My Own Life, p. XXX). Ao mesmo tempo, no entanto, foi com base nessa extensa análise documental que ele pode justificar as suas pretensões de imparcialidade. 
a massa monolítica dos documentos que formam os anais da história dos saxões é vista por ele como pertencendo a um período "obscuro e desinteressante" (HE I, p. 4), o que explica a sua supressão na História da Inglaterra e a sua substituição por uma narrativa capaz de "prometer entretenimento e instrução aos leitores" (idem). Os primeiros leitores de Hume souberam valorizar esse cuidado com o estilo, mas também desconfiaram da propriedade de suas argumentações. Desde a primeira edição, o texto sofreu numerosas - e muitas vezes violentas - críticas contra a imprecisão ou falsidade dos fatos narrados nele. Hume parece mesmo ter levado muitas delas em consideração, corrigindo o texto em edições posteriores. No entanto, nenhuma revisão foi mais ampla que aquela relacionada ao estilo. Quando, em 1768, o pastor Joseph Priestley publicou seu Rudiments of English Grammar, listando mais de cem passagens da História da Inglaterra como exemplo de escrita ruim, Hume primeiro reagiu negativamente, mas, enfim, acatou a maior parte das revisões sugeridas (cf. FIESER, 2005c, p. XXII).

Percebemos, assim, que Hume estava interessado no testemunho histórico, mas apenas enquanto narrativa e não enquanto fundamento. O seu próprio método para ajuizar a legitimidade desses testemunhos é extremamente sintomático sob esse aspecto. Em primeiro lugar, ele deixa de fora a questão da origem, substituindo-a pela regularidade das paixões. Ao se deslocar para o nível da narrativa, começo e fim partilham de um mesmo estatuto filosófico, embora distantes no tempo: o que o experimento do Tratado encontra no fim é essa natureza humana como estabilidade, algo que era, ao mesmo tempo, condição do experimento. É nesse sentido que as "causas morais", compreendidas no sentido estabelecido pelo Tratado, são as únicas razões utilizadas para rejeitar a tese de historiadores como Isaak Vossius ou Montesquieu, que pretendiam demonstrar que a população do mundo antigo era maior que a do moderno (cf. Essays, p. 383). Trata-se, portanto, como afirma David Wooton, da aplicação do método experimental sobre os "princípios filosóficos envolvidos no estabelecimento do testemunho" (WOOTON, 2009, p. 458) e não sobre o conteúdo desses. Esse mecanismo já está em jogo no texto que Hume havia escrito antes mesmo do Tratado, o seu An Historical Essay on Chivalry and Modern Honour, onde as monstruosidades das práticas da cavalaria romântica são deduzidas "da necessária operação dos princípios da natureza humana" 27 .

27 Hume, apud Mossner, 1946, p. 57. Há uma grande divergência quanto à data de redação do texto e quanto à sua finalidade. A hipótese desqualificadora, que afirma tratar-se de um texto escolar, no entanto, não se sustenta, já que o tema reaparece, muitas décadas depois, em um tratamento semelhante, nos últimos parágrafos do Apêndice II da História da Inglaterra (cf. HE I, Ap. II, p. 487-488). 
Em segundo lugar - o que pode parecer especialmente estranho para os rankeanos -, a crítica das fontes históricas operada por Hume se fundamenta em uma concepção de história que tem uma relação com o tempo secundária. Ou seja: o mecanismo através do qual impressões e ideias se sucedem de modo selvagem e, em seguida, se estabilizam sob a forma de uma síntese (causa, identidade, história) não deve ser lido tanto verticalmente, de modo que o objeto ao final apresente a sua longa evolução (antropológica, psicológica, política), mas, antes, horizontalmente, na medida em que esse objeto reflete a sua posição em um quadro taxonômico geral, imutável - o que o aproximava da ideia de uma história natural como foi desenvolvida no século 17 e que Michel Foucault procurou descrever (cf. FOUCAULT, 1966, p. 140-176). Nesse sentido, a posição de Hume na abertura do atual primeiro volume da História da Inglaterra é explícita: enquanto a história se preocupar com o caráter temporal dos fatos, está condenada a se perder na "obscuridade, incerteza e contradição" (HE I, I, p. 3). Ao invés dessa abordagem, Hume propõe a sua análise horizontal: "Os únicos meios corretos através dos quais as nações podem desfrutar a sua curiosidade em pesquisas em relação à sua origem remota é considerar a linguagem, as maneiras e os costumes de seus ancestrais, e compará-los com os de suas nações vizinhas" (HE I, I, p. 4). Não uma antropologia histórica - se é que a ideia heuristicamente delimitada de antropologia já faz sentido aqui -, mas uma história antropológica. É ilustrativa dessa abolição do tempo a exceção que a História da Inglaterra admite diante da regra que exige do historiador distência em relação a narrativas fantasiosas que partem de uma origem mitológica. Hume concede que certo cuidado deva ser mantido, mas permite que as ficções da Grécia Antiga sejam levadas em conta no estabelecimento das fontes históricas. $O$ que as pemite entrar nesse espaço não é, obviamente, a sua determinação temporal - o que lhes permitiria serem tratadas como fatos -, mas o consenso e a paixão moderadora que elas veiculam. Elas se tornam legítimas na medida em que ultrapassam o limite na direção de uma "história verdadeira" - porque são "tão celebradas e tão agradáveis" (p. 4). Mais importante que outras fições quaisquer, a mitologia grega não é apenas o fruto de uma natureza humana imatura, mas, positivamente, um limite incontornável no quadro de classificações das ações que constituem os valores morais do ser humano.

Assim como a causalidade não pode ser explicada somente pela repetição das impressões no tempo, mas deve, além disso, ser instanciada no hábito, também a história não se restringe à sucessão dos fatos, mas se realiza mais precisamente na estabilização da narrativa. Se a historiografia de Hume pode ser - como comumente foi (cf. MEYER, 
1958) - comparada à de Voltaire, então ela o pode precisamente sob esse aspecto. No verbete História, escrito por Voltaire para a Encyclopédie, a questão do estilo narrativo é absolutamente central:

o método conveniente à história de vosso país não é próprio para escrever as descobertas do novo mundo. Não escrevei sobre uma cidade como sobre um grande império, não fazei [a história] de um indivíduo como escreveis a história da Espanha ou da Inglaterra. [...] Essas regras são bem conhecidas. Mas, a arte de escrever bem a história será sempre muito rara. Sabe-se que é necessário um estilo grave, variado, agradável [...] (VOLTAIRE, 1765, p. 225).

Porém, o pirronismo histórico de Voltaire não se limita a propor uma máxima estilística; mais fundamentalmente, ele repete a distinção operada por Hume entre narrativa e origem. No caso de Voltaire, isso significou afirmar que a história não se ocupava do passado, mas da perenidade da razão humana - objeto fora do tempo, que em termos humeanos corresponderia à natureza. É assim que o Elogio histórico da razão, texto de 1774, se apresenta sob a forma de uma narrativa fabulosa, onde a Razão e a Verdade são personagens mitológicos (cf. VOLTAIRE, 1877, p. 512-522). No discurso lendário, a narrativa se manifesta em sua pura narratividade, desancorada do tempo. O elogio histórico da razão, de Voltaire, e poderíamos dizer também de Hume, é a antítese do elogio da razão histórica. A identidade do fato com o discurso, que abriu a narrativa para a hermenêutica e a natureza humana para a Geisteswissenschaft romântica, está incontornavelmente ausente do modelo histórico-filosófico de Hume; mas, na medida em que se encontra irremediavelmente no nosso, talvez tenhamos de continuar lendo a História da Inglaterra como um fruto estranho e tardio do autor do Tratado.

\section{Referências}

BEAM, C. "Hume and Nietzsche: Naturalists, Ethicists, Anti-Christians". In: Hume Studies, XXII:2 (1996), p. 299-324.

BECK, L. W. Essays on Kant and Hume. New Haven - London: Yale University Press, 1978.

BENTLEY, M. "Introduction: Approaches to Modernity: Western Historiography since the Enlightenment”. In: BENTLEY, M. (Ed.). Companion to Historiography. London New York: Routledge, 1997, p. 379-475.

CAPALDI, N. "Hume as Social Scientist". In: TWEYMAN, S. (Ed.). David Hume Critical Asessments. London - New York: Routledge, 1995. Vol. VI.

COLINGWOOD, R. G. The Idea of History. Oxford: Oxford University Press, 1955.

CONNIFF, J. "Hume on Political Parties: The Case for Hume as a Whig". In: EighteenthCentury Studies, 12:2 (1978-1979), p. 150-173. 
DELEUZE, G. Empirisme et subjectivité. Paris: PUF, 1993.

EMERSON, R. L. Essays on David Hume, Medical Men and the Scottish Enlightenment. Farnham: Ashgate, 2009.

ESKILDSEN, K. R. “Leopold Ranke's Archival Turn: Location and Evidence in Modern Historiography". In: Modern Intellectual History, 5:3 (2008), p. 425-453.

FIESER, J. A Bibliography of Hume's Writings and Early Responses. Bristol: Thoemmes Press, 2003.

. Early Responses to Hume. Bristol: Thoemmes, 2005a. Vol. 2 - Early Responses to Hume's Moral, Literary and Political Writings II.

. Early Responses to Hume. Bristol: Thoemmes, 2005b. Vol. 3 - Early Responses to Hume's Metaphysical and Epistemological Writings I.

. Early Responses to Hume. Bristol: Thoemmes, 2005c. Vol. 7 - Early Responses to Hume's History of England I.

FORBES, D. Hume's Philosophical Politics. Cambridge: Cambridge University Press, 1975.

. "Hume's Science of Politics". In: MORICE, G. P. (Ed.). David Hume Bicentenary Papers. Edinburgh: Edinburgh University Press, 1977.

FORCE, J. E. "Hume's Interest in Newton and Science". In: Hume Studies, XIII:2 (1987), p. 166-216.

FOUCALUT, Michel. Les mots et les choses. Paris: Gallimard, 1966.

GRENE, M. "Hume: Sceptic and Tory". In: Journal of the History of Ideas, 4 (1943), p. 333-348.

HICKS, Ph. "Bolingbroke, Clarendon, and the Role of the Classical Historian". In: Eighteenth Century Studies, 20:4 (1987), p. 445-471.

HUME, D. A Dissertation on the Passions; The Natural History of Religion. Oxford: Ed. by Tom Beauchamp, Oxford University Press, 2007 [=Diss.].

A Treatise of Human Nature. London: Ed. by David Fate Norton and Mary J. Norton, Oxford Univeristy Press, 2005 [ = T, seguido dos números correspondentes a parte, livro, seção e parágrafo].

An Enquiry concerning the Human Understanding. Oxford: Ed. by Tom Beauchamp, Oxford University Press, 1999 [=EHU, seguido dos números correspondentes à seção e ao parágrafo].

. An Enquiry concerning the Principals of Morals. Oxford: Ed. by Tom Beauchamp, Oxford University Press, 2005 [=EPM, seguido do número correspondente à seção]. [= Essays].

Essays Moral, Political and Literary. Indianapolis: Liberty Funds, 1985

. The History of England. Indianapolis: Liberty Funds, 1983. 6 v. [= HE, seguido dos números correspondentes ao volume, capítulo e página].

The Letters of David Hume. London: Oxford University Press, 1932. 2 v. [= Letters, seguido do número correspondente ao volume].

JONES, P. Hume's Sentiments. Their Ciceronian and French Context. Edinburgh: The Edinburgh University Press, 1982. 
KEMP-SMITH, N. "Kant's Relation to Hume and to Leibnitz". In: The Philosophical Review, 24:3 (1915), p. 288-296.

The Philosophy of David Hume: A Critical Study of Its Origins and Central Doctrines. London: Macmillan, 1941.

KIDD, C. Subverting Scotland's Past: Scottish Whig Historians and the Creation of an Anglo-British Identity, 1689-c. 1830. Cambridge: Cambridge University Press, 1993.

MALHERBE, M. Kant ou Hume ou la raison et le sensible. Paris: Vrin, 1993.

. La philosophie empiriste de David Hume. Paris: Vrin, 1992.

MEYER, P. H. "Voltaire and Hume as Historians: A Comparative Study of the Essai sur les moeurs and the History of England". In: PMLA, 73:1 (1958), p. 51-68.

MOSSNER, E. C. "An Apology for David Hume, Historian". In: PMLA, 56:3 (1941a), p. 657-690.

. "David Hume's 'an Historical Essay on Chivalry and Modern Honour". In: Modern Philology, 45:1 (1947), p. 54-61.

. The Life of David Hume. New York: Oxford University Press, 1980.

. "Was Hume a Tory Historian? Facts and Reconsiderations". In: Journal of the History of Ideas, 2:2 (1941b), p. 225-236.

NORTON, D. F. "History and Philosophy in Hume's Thought". In: NORTON, D. F.; POPKIN, R. (Eds.). David Hume: Philosophical Historian. Indianapolis: Bobbs-Merrill, 1965.

NOXON, J. Hume's Philosophical Development - A Study of his Methods. London: Oxford University Press, 1973.

OKIE, L. Augustan Historical Writing - Histories of England in the English Enlightenment. Maryland: University Press of America, 1991.

PARUSNIKOVA, Z. "Against the Spirit of Foundations: Postmodernism and David Hume". In: Hume Studies, XIX:1 (1993), p. 1-18.

PEARS, D. "Hume's Empiricism and Modern Empiricism". In: PEARS, D. (Ed.). David Hume - A Symposium. New York: St. Martin's Press, 1966, p. 11-30.

. Hume's System - An Examination of the First Book of his Treatise. New York:

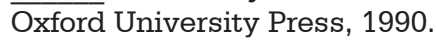

PHILLIPS, M. S. "Distance and Historical Representation". In: History Workshop Journal, 57 (2004), p. 123-141.

. Society and Sentiment: Genres of Historical Writing in Britain, 1740-1820. Princeton: Princeton University Press, 2000.

. The Most Illustrious Philosopher and Historian of the Age: Hume's History of England. In: RADCLIFFE, E. S. (Ed.). A Companion to Hume. Oxford: Wiley-Blackwell, 2011, p. 406-422.

POPKIN, R. "Skepticism and the Study of History". In: NORTON, D. F; POPKIN, R. (Eds.). David Hume: Philosophical Historian. Indianapolis: Bobbs-Merrill, 1965, p. IX-XXXI.

RADCLIFFE, E. "Introduction". In: RADCLIFFE, E. S. (Ed.). A Companion to Hume. Oxford: Wiley-Blackwell, 2011, p. 1-18.

RANKE, L. von. Englische Geschichte, vornehmlich im siebzehnten Jahrhundert. 3 Bände. Leipzig: Duncker und Humblot, ${ }^{2} 1870$. 
RANKE, L. von. Geschichte der romanischen und germanischen Völker von 1494 bis 1514. Leipzig: Duncker und Humblot, 1885.

RUSSELL, P. Freedom and Moral Sentiment - Hume's Way of Naturalizing Responsibility. London: Oxford University Press, 1995.

SABINE, G. H. "Hume's Contribution to the Historical Method". In: The Philosophical Review, 15:1 (1906), p. 17-38.

SAPADIN, E. "A Note on Newton, Boyle, and Hume's 'Experimental Method'”. In: Hume Studies, XXIII:2 (1997), p. 337-344.

STEWART, M. A. "Hume's Intellectual Development 1711-1752". In: FRASCA-SPADA, M.; KAIL, J. P. E. (Eds.). Impressions of Hume. Oxford: Oxford University Press, 2005, p. 11-58. STRAWSON, P. F. Freedom and Resentment and Other Essays. Oxford: Routledge, 2008a.

. Skepticism and Naturalism: Some Varieties - The Woodbridge Lectures, 1983.

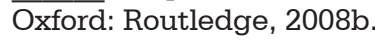

TODD, W. B. Foreword. In: HUME, D. The History of England. Indianapolis: Liberty Funds, 1983. Vol. 1, p. XI-XXIII.

TREVOR-ROPER, H. R. "David Hume: Politico e Storico by Giuseppe Giarrizzo (review)". In: History and Theory, 3:3 (1964).

. "Hume as Historian". In: PEARS, D. F. (Ed.). David Hume - A Symposium. New York: St. Martin's Press, 1966.

VOLTAIRE. Éloge Historique de la Raison. In: Oeuvres complètes. Paris: Garnier, 1877. Tome XXI.

. "Histoire". In: Encyclopédie, ou Dictionnaire Raisonné des Sciences, des Arts et des Métiers, par une Société de Gens de Lettres. Neufchastel: Chez Samuel Faulche \& Compagnie Libraires \& Imprimeurs, 1765. Tome Huitième (H-IT), p. 220-225.

WARREN, J. "The Rankean Tradition in British Historiography, 1840 to 1950". In: BERGEN, S. et al. Writing History - Theory and Practice. New York: Oxford University Press, 2003.

WERTZ, S. K. Between Hume's Philosophy and History: Historical Theory and Practice. Maryland: University Press of America, 2000.

p. 261-287.

"Collingwood's Understanding of Hume". In: Hume Studies, XX:2 (1994),

WOODWARD, J. An Attempt Towards a Natural History of the Fossils of England. London: Fayram, 1729. Vol. 1.

WOOTON, D. "David Hume: 'The Historian'”. In: NORTON, D. F.; TAYLOR, J. (Eds.). The Cambridge Companion to Hume. Cambridge: Cambridge University Press, ${ }^{2} 2009$, p. 447-479.

\section{Endereço postal:}

Fabiano Lemos

Rua Senador Vergueiro 138, apto. 204 - Bairro Flamengo

22230-001 Rio de Janeiro, RJ, Brasil 